\title{
Theatricality and Drifting in the Anthropocene:
} Reading Asger Jorn and Guy Debord's Mémoires as 'earth book'.

\section{CARL LAVERY}

\begin{abstract}
This essay proposes a new way of reading the Situationist notion of dérive (drift) in the Anthropocene by thinking of it as an operation that is geological in impetus, a sense of movement caused by an agentic earth. Equally, it looks to offer an alternative and expanded theory of theatricality in which the theatrical is no longer associated with theatre per se. On the contrary, it is now seen as a mode of representation that deterritorializes spectators by placing them in the midst of groundless flows and anonymous processes. In the same way that the earth in the Anthropocene is figured as a dynamic and unstable planet, so drifting and theatricality, when brought together, radicalise our extant understandings of the stage by allowing it to become motile, a terrestrial force. Here, the ecological potential of theatre is not found in staging plays about climate change or insisting on site-specificity, but in thinking through the geological power of theatricality, its capacity to exist as a type of plate tectonics. Such an expanded understanding of theatricality explains why instead of paying attention to a specific theatre production or even to the medium of theatre in a restricted sense, I examine how, in their 1958 text and image collaboration Mémoires, the Danish artist Asger Jorn and his friend Guy Debord were able to transform the page into a stage - to theatricalize and geologize reading. In an attempt, simultaneously, to expand and undo itself, the article is not content to conceptualize its argument, it looks to theatricalize itself, to become a kind of drift, a geology of writing.
\end{abstract}

\section{KEYWORDS}

Theatricality, Ecology, Dérive (Drift), Anthropocene, Geology, Asger Jorn, Guy Debord, Mémoires, Deterritorialization 


\section{Theatricality and Drifting in the Anthropocene: Reading Asger Jorn and Guy Debord's Mémoires as 'earth book'.}

This is a theatricalized essay that moves and shifts - like a kind of geologic drift, or the movement of plate tectonics. Its seven parts are conceived as continents that buffer and collide with each other, and the 24 paragraphs, too, are numbered and proposed as floating islands or 'plates'. The usual smoothness or organic 'unfoldings' that structure what is generally considered to be an elegant argument are deliberately underplayed, even if a linear way of thinking is not dispensed with - perhaps because to do so would result in too-wild a destratification, a type of intellectual chaos. The aim of this textual exercise is to allow my thinking to show its seams as well as to create unexpected collisions between ideas, perceptions, and intuitions. And it is here, in this experimentation in form and style, where the theatricality of the text is found: that is to say, in its potential for mimesis, for becoming the thing it wants to discuss, but in such a way that the logic of its compositional strategies is shown. It seems important to note that theatricality is not equated with performativity in this essay. Whereas performativity, as we know from J.L. Austin through to Judith Butler, (re)produces the world through iteration, theatricality, as I go on to explain, looks to suspend production, to disclose a gap or emptiness at the heart of any signifying system - a fact which explains why I keep the Anthropocene as a heuristic and ultimately highly theatrical referent.

\section{The Poverty of Nomenclature 1}

1. The Anthropocene is a controversial term. Not only because its very existence is contested, but because its causes are so difficult to determine. ${ }^{2}$ For Paul J.

\footnotetext{
1 This title is borrowed from an essay by Eileen Crist, 2016.

2 The term has been recommended but not accepted by the International Geological Congress. For the working group of experts who support the naming of a new geological epoch, the Anthropocene has been dated to 1950 and is coterminous with both the 'great acceleration' in fossil fuel burning that has continued to explode since 1945 as well as the start of the nuclear age. Others, however, trace its origins to a number of different causes: the invention of the steam engine in the late eighteenth century, to Columbus's conquest of the Americas and the start of the
} 
Crutzen and the earth scientists who form part of the International Commission on Stratigraphy, the Anthropocene is a signifier for a planet whose geology has been irrevocably changed - terraformed - by anthropogenic actions. In particular, the fall out produced by carbon burning, petro-chemical usage, and nuclear testing. ${ }^{3}$ Others more directly concerned with politics and ethics locate the meaning of the Anthropocene within a wider history of capitalism, patriarchy, racism, and colonialism. Critical readings such as these have led to a crisis in nomenclature, with some critics introducing new terms in a better attempt to apportion socio-economic blame - some of the most popular of which have been the Capitolocene,${ }^{4}$ the Technocene, ${ }^{5}$ the Chthulucene,${ }^{6}$ and the Neganthropocene. ${ }^{7}$ While this proliferation in nomenclature seeks to provide a less neutral, more historically focused lens for investigating an earth beset with species extinction, global warming, and increasing levels of toxification, there is nevertheless a problem in such a drive to classify and trace back. Ironically, each of these nominations compromises the ecological logic that they purport to champion. By positing an origin, an/or naming a definite starting point, they cause readers to forget that in 'nature' everything is multiple and differential, and from the very beginning. Nothing comes from nothing, and in a chaotic, emergent world, 'causes' cannot be so easily discerned or dated, even if some factors - most notably, the energy needed for capitalist modernity - weigh more heavily than others.

2. The point is not to abandon the term Anthropocene for some supposedly, more accurate word, but to use it as a place holder, a decidedly theatrical sign for something that is wholly provisional, knowingly artificial, and not what it seems. As a consequence of this theatricalization, two factors hopefully come to the fore. First, a recognition that the Anthropocene is a complex phenomenon that needs to be understood in terms of what Félix Guattari names "a transversal", a line that cuts across and intersects different identities, histories, theories, and practices. $^{8}$ Second, that energy is not spent on critical diagnosis alone but, in parallel with Gilles Deleuze's notion of art, is deployed "clinically". ${ }^{9}$ That is to say as a therapeutic, a way of de-structuring and restructuring the world that would pragmatically sacrifice mere knowledge (connaissance), for the sake of producing new, more generative ways of existing with human and nonhuman others. For if the Anthropocene cannot be dated with any real precision

'Columbian exchange', and to the development of agriculture and burning of forests in prehistory. For a comprehensive overview of the theories and histories of the Anthropocene, see Bonneuil and Fressoz, 2015.

3 The Anthropocene finds its etymology in the conjunction of anthropos (man) with cene (new). It translates as the new age of man, and its name dates from Italian geologist Antonio Stoppani's 1873 work on what he initially called "the anthropozoic era". See Crutzen, 2002, 23.

4 Moore, 2016.

5 Hornborg, 2015.

6 Haraway, 2016.

7 Stiegler, 2018.

8 Guattari, 2008, 29.

9 Deleuze, 1998, Iv. 
geologically and/or traced to a single historical process or set of anthropogenic practices, this does not mean that it is not happening. Like a Derridean ghost, the Anthropocene is always already here.

3. The Anthropocene is a signifier for a revolution in how the planet is thought, figured and experienced in extant environmental thinking or 'green philosophy'. In the Anthropocene, the earth is neither an unchanging ark to protect, as phenomenologist philosophers Edmund Husserl and Martin Heidegger thought; nor is it a tranquil blue marble that human beings can marvel at from a distance as the famous image taken in 1972 by the Apollo 17 Space Mission tended to suggest. There is, then, if not entirely a loss of innocence in the Anthropocene, then certainly a radical diminution in our capacity to represent 'nature' as a benign or wholly positive force, as so many ecophilosophical thinkers have done and continue to do. For what the Anthropocene tells us is that the earth is a mass of flowing magma, continually thrown off course and re-invented, both internally and externally, by the shifts and collisions of plate tectonics, meteor strikes and radical fluctuations of weather and temperature. The earth is multiform, never one. ${ }^{10}$

4. To see the earth as a dynamic, heterogeneous planet, predicated on indifferent movement and vast revolutions, transforms, necessarily, our ways of existing on it. ${ }^{11}$ For to live on the earth, as Deleuze and Guattari specify in their readings of "sedentary", "holey" and "nomadic space", is always to mark it, to establish territories, to demarcate areas of belonging and identity. ${ }^{12}$ Equally, it is to invest in modes of what a Marxist terms "metabolistic exchange", processes that place the human animal - the anthropos - within a vast, incalculable and unpredictable system of energy circulation, implicating inorganic, organic, and machinic life in a common flow. ${ }^{13}$ Such a flow gives rise to uncontrollable feedback loops that impact all forms of life, cultural as well as terrestrial. The ultimate irony of the Anthropocene - and hence an additional reason why I retain its troublesome name in this essay - is that it articulates the suspensive, impossible moment when arrival is simultaneously a departure, when the human becomes the 'more than human' that it always was, and when accepted notions of time and space are placed in doubt, queered. As critical theorist Tom Cohen explains: "[T]he 'Anthropocene' can only be named from without or after, as if by another looking back [...]. Some eye, or some thing, must witness and confirm this arc, this mark in geomorphic and biomorphic time. It, the term, implies a species consciousness marking its disappearance." 14

\section{Complexities}

5. The uncanny temporality that Cohen draws attention to poses serious

10 See, for instance, Clark, 2011, and Clark and Yusoff, 2017.

11 Since the nineteenth century geology has been aware that there is not one earth, but many.

12 Deleuze and Guattari, 1987, 474-500.

13 Bellamy Foster, $1999,367$.

14 Cohen, 2012, 243; original italics. 
questions for artists who want to engage with ecological content in normative ways. For the timescales of the Anthropocene not only thwart standard naturalist tropes of mimesis, they also highlight the anthropocentrism of all attempts to narrate and/or figure the world as a meaningful construct or self-evident image. In his discussion of climate change, arguably the signature feature of the Anthropocene, Timothy Clark cautions that: "The newly counter-intuitive demands on representation being made by issues such as climate change mean that ... still-dominant conventions of plotting, characterisation and setting in the novel need to be openly acknowledged as pervaded by anthropocentric delusion, and that environmental thinking would be stronger if it explored more directly and aggressively the drastic nature of the cultural break that recognising this may entail." 15

The aesthetic crisis which the Anthropocene inflicts upon representation Clark goes so far as to term it "a disorder" - is particularly difficult for dominant, western modes of theatre to respond to. ${ }^{16}$ For in that tradition - and I am thinking, in particular, of the tragic form that runs from Sophocles via Shakespeare to Sarah Kane - the human being has largely been figured as the central agent, the only animal that counts. In Aristotelian and neo-Aristotelian theatre, much attention has been given to psychology, speech, characterisation, and teleological structure. And from the bourgeois dramaturgical revolution of the eighteenth century onwards, there has been an important tradition of teaching associated with drama, with the stage posited as a cultural technology for shaping bodies and minds through the restoration of human behaviour patterns and gestures. But none of these attributes are applicable to the Anthropocene, an epoch that confronts humanity with the spectre of an autonomous earth. As such, it is no surprise to find that many theatre and performance makers today have started to reject the anthropocentrism of the western stage, and to work instead with animals, elemental matter, machines and objects. One thinks, for instance, of Societas Raffaello Sanzio, Kris Verdonck, Gisèle Vienne, Mike Brookes and Rosa Casado, and Philippe Quesne, all of whom posit the human as only one actant in a network of things, prostheses, and other creatures.

6. There has been an equally significant shift in theatre and performance theory, with scholars turning away from cultural notions of identity and instead engaging with the 'more than human fields' of animal studies, technology, and, most pertinently, in this context, ecology and environment. ${ }^{17}$ Wendy Arons and Theresa J. May claim that "ecodramaturgy" ought to put "ecological reciprocity and community at the centre of its theatrical and thematic intent"; ${ }^{18}$ Bonnie Marranca looks to link "ecology and aesthetics in the search for newer and deeper kinds of knowledge that outlines the biocentric worldview in certain

15 Clark, 2015, 191.

16 Ibid., 195.

17 See, for instance, Kershaw on ecology, 2007; Orozco on animals, 2013; Schweitzer and Zerdy on objects, 2014; Braddock on animism, 2017; and Salazar Sutil on matter, 2018.

18 Arons and May, 2012, 4. 
works"; 19 and Una Chaudhuri, in her prolific and influential body of writing in this area, is concerned to outline "an ecological imperative" founded in a non-metaphorical encounter with elemental nature. ${ }^{20}$ However, despite their admirable intentions to widen the performance commons, these thinkers ultimately fail to address the crisis of thought - and I stress that phrase that the Anthropocene has brought into being. In their entirely understandable urgency to develop an ecologically-focused mode of theatre criticism, they place insufficient emphasis on interrogating the human, in underscoring its precarity, its failure to know. Too often in their work, the human is proposed as the animal that, to borrow from Matthew Goulish and Stephen Bottoms, can "repair" the destruction it has wrought on the earth through intentional or quasiactivist acts. ${ }^{21}$ I take a different position; one in which more might be gained by recognising our helplessness in the face of a violent earth, in surrendering to our lack of knowledge, in not being so militant in our compulsions to act, save, restore. In this respect, my argument has, perhaps, more in common with Baz Kershaw's interest in 'paradoxology' and 'double-binds', ${ }^{22}$ and Alan Read's commitment to extinction, failure, and 'natural history'. ${ }^{23}$ Here, the strength of theatre and performance resides in its weakness, and its openness to chance, contradiction, and disappointment. However, where Kershaw and Read equate natural history with animals (as indeed does Chaudhuri), in their ecologically driven forms of theatre theory, I approach it geologically, as a matter of/for tectonic earth-systems. ${ }^{24}$

\section{Theatricality}

7. Theatricality is a complex word with diverse and contested meanings within the disciplines of Theatre and Performance Studies. ${ }^{25}$ Like theatre, the practice it is conventionally associated with, theatricality is always provisional, haunted by an absence in the very act of making present, an opacity at its centre, a beginning in its end. For Erika Fischer-Lichte and Josette Féral, theatre is a semiotic practice that shows its showing, a form of mimesis that never disappears in its appearing. ${ }^{26}$ Nevertheless, despite this close proximity, theatricality, as the sociologists Elizabeth Burns and Erving Goffman knew, is not confined to theatre alone (although neither can it be separated from it once and for all). Rather, to draw extensively from Samuel Weber's text Theatricality as Medium (2004), and in an attempt to make use of its theoretical potential for ecocriticism, I approach theatricality as both a medium in itself and a particular way of thinking that departs from western philosophy's "presumption of self-

19 Marranca, 1996, xvi.

20 Chaudhuri, $1995,83$.

21 Bottoms and Goulish, 2007, 1.

22 Kershaw, 2007, 11.

23 Read, 2009, 249-79.

24 See Chaudhuri, 2016.

25 For an excellent account of the multiple meanings inherent in the word theatricality as well as its historical shifts, see Tracy C. Davis and Thomas Postlewait's 'Introduction' to their edited collection Theatricality, 2003, 1-39.

26 See Féral, 2002, 94-103, and Fischer-Lichte, 1995, 85-9. 
identity and self-presence". ${ }^{27}$ As medium more than genre, theatricality, for Weber, can be applied to other forms such as literature, cinema, installation art, sculpture, etc. - any artistic practice, then, that is self-conscious about its mode of signifying, that stages itself, and demands an audience. Where western metaphysics invests in a 'ground' for thinking, adopting a logic of origins and ends (arche and telos), theatricality, by contrast, deterritorializes. In doing so, it discloses a radical difference - "a hollow place", Weber calls it - at the very heart of identity that opens the human to a troubling outside which is always on the inside, a non-human fold that unwittingly and oxymoronically remains in relation by departing. ${ }^{28}$ Weber notes: "All of this is uncannily condensed in the English phrase parting with. The "with" suggests that parting entails a departure, not simply as the dissolving of a relationship, but rather as a singular way of (re)constituting one. To remain in relation with precisely by parting [...]." ${ }^{29}$

8. Through its partitioning, theatricality suspends the metaphysical nexus that holds together accepted notions of time, space, and identity. Its time is that of the present participle, a form of temporality that passes but never arrives - elusive, suspensive, and interruptive. Weber provides an insightful account of the ontological and epistemological disjunctions wrought by the present participle in his parsing of Jacques Derrida's reading of Stéphane Mallarmé's pirouetting ballerina: "What is curious about the present participle is the way it is both very close and yet irreducibly remote. Since it never adds up to a whole and always remains a part, the participation it entails follows a trajectory like that of a ballerina in another text of Mallarmé. Her pirouette, as Derrida shows, revolves incessantly around a center that is displaced with each turn, never coming full circle, never adding up to a whole nor even to a simple step forward." 30

Weber's deconstructive notion of theatricality has distinct purchase in the Anthropocene. Not only does theatricality, in his reading, 'unground' anthropocentric notions of time and space - frameworks habitually used to domesticate the earth - it can also attune audiences to a different way of existing with and on the planet. It does so by positing being as something ungraspable, caught up in an immanent process of endless transformation and splitting in and from itself.

9. In his discussion of "Autumn River", a sequence from Peking Opera performed in Beijing by the Liyuan Theatre Company in 1999, Weber describes how the characters, Chen and the Boatman, lack all interiority. These protagonists are not individuals in the sense that Aristotle specifies in The Poetics and that

27 Weber, 2004, 67. I am drawn to Weber's account since, for him, theatricality has both epistemological and ontological significance. It troubles human-centered ways of being in a fundamental manner and opens the human to the non-human. This ontological dimension of theatricality is not so pronounced in either Féral (1995), Fischer-Lichte (1995), Burns (1972), or Goffman (1990). My contribution is to give Weber's formulation of the term an ecological 'twist'.

28 Ibid., 5.

29 Ibid., 19; original italics.

30 Ibid., 15-16. 
western drama has never tired of producing. Rather, they are hosts of/for gestures that come from elsewhere. Instead of moving, they allow themselves to be moved by their environment - in this instance, the river: "The performers in this scene do not appear primarily as individuals. Neither passive nor active in the Western sense, they demonstrate, quite literally, a way of being moved that confounds such oppositions. The skill of the performer allows a movement to be deployed that can never be reduced to the property or product of an individual qua individual." 31

In what Weber refers to as a "ballet of balance", our attention is not fixed on agonistic competition between the characters - the tragic agon that structures western dramaturgy - but rather on how Chen and the Boatman are able to leave the "support of the land behind" and find a way of negotiating the river. ${ }^{32}$ This theatrical departure from the fixity of a ground - this affirmation of what Weber elegantly terms the "sway of being"- permits a different mode of being on the earth to reveal itself. ${ }^{33}$ Caught in the agency of the river's flows and currents, the protagonists are "content to respond rather than to impose and resist." ${ }_{4}$ And it is precisely here, I want to propose, in this acknowledgement of a lively environment, this awareness of the need to find a different kind of balance on an always motile earth, that theatricality posits itself as a medium that has much to contribute to new ways of being a subject in the Anthropocene. Crucially, the point, as Weber never tires of repeating, is not to tell stories, but to disclose, through bodily gesture, what it means to exist on an impersonal, agentic planet, to respond to its gravity and weight, to open oneself to its capricious and unpredictable flux, its propensity for catastrophe.

10. For Weber, the spectator, though seated in the auditorium, undergoes a similar experience to Chen and the Boatman on the river. In this unashamedly theatrical staging, we do not stand apart from what we see. We, too, are unmoored, involved in an affective transaction, implicated in the pathos (not the mythos) of a stage that appears alive, infused with its own matterenergy. Theatrical vision, for Weber, is always corporeal and opaque. The eye, he reminds us, is touched "with an ineradicable macula, a stigma or stain that cannot be cleansed, or otherwise rendered transparent, diaphanous". ${ }^{35}$ Theatricality, then, situates the spectator in an earthy and affective milieu that problematizes the so-called efficiency of any sign system by foregrounding the non-human matter, the earthliness that cannot be figured in it. This blindness is notably why, in Weber's reformulation and expansion of the term, theatricality cannot be delimited to the art form called theatre alone. Henceforth, theatricality is a medium in itself, something that 'grounds' and 'ungrounds', that makes meaning and identity drift, just like Chen's river, in other words - or indeed the earth itself. If performativity gives birth to a world, theatricality makes it tremble

31 Ibid., 27; original italics.

32 Ibid., 28.

33 Idem., original italics.

34 Idem.

35 lbid., 7. 
in the very act of constructing it. Theatricality's decidedly heterogeneous way of thinking is in tune with the findings of contemporary geology, most of which highlight the multiplicity of the earth, its protean capacity to give birth to itself again and again. ${ }^{36}$

\section{Mémoires}

11. This investigation of theatricality as non-human force, a molecular haze or elemental energy inherent to any act of semiosis, explains why instead of paying attention to a specific theatre production or even to the medium of theatre in a restricted sense, I want to examine how, in their 1958 collaboration Mémoires, the Danish artist Asger Jorn and his friend Guy Debord, the spokesperson for the Paris-based section of the Situationist International (SI), were able to transform the page into a stage - to theatricalize reading. ${ }^{37}$

12. Developing and intensifying early twentieth-century Futurist and Dadaist experiments in typography, Mémoires is a fragmented text and image piece of 55 pages, without numbers or coherent narrative structure. On the pictorial level, it is composed of an anarchic assemblage of photographs, diagrams, maps, ground plans of buildings, cut-outs from newspapers, and soft porn magazines. All of these images are arranged against a stunning background of chromatic spillages and daubings that are referred to architecturally as "structures portantes" ("foundational structures"). ${ }^{38}$ To achieve this anarchic effect, Asger Jorn, in a humorous take on Jackson's Pollock's action paintings, dripped ink and paint onto the plates from a ladder positioned above. Structurally, the book is divided into 3 sections, charting the 18 months between June 1952 and December 1953, and documenting the people, places, practices, and events involved in the creation of the Lettriste International avant-garde group in Paris. Although the text calls itself a memoir, a genre of writing usually associated with depicting and chronicling the inner life of a given author, Mémoires, boldly and confusingly, advertises itself on the cover as being composed of "éléments préfabriqués" ("prefabricated elements"). ${ }^{39}$

13. As well as navigating the pages visually, readers are also confronted with a dizzying array of texts from newspapers, fashion magazines, plays, poems, and novels, with Shakespeare, Corneille, Thomas de Quincy, and Robert Louis Stevenson featuring prominently. In line with the Sl's concept of détournement, none of the sources are given for the citations, thus allowing the fragments

36 For an accessible account of the theories of the new geology, see Clark and Yusoff, 2017, 3-23.

37 Although their 1957 piece Fin de Copenhague [The End of Cophenhagen] may appear more apposite for this journal, with its focus on Scandinavia, I have preferred to place Mémoires at the heart of my essay, since, as I will explain, it establishes theatricality as an alternative form of 'doing' geology. In this text, the fixity of stratigraphy is replaced by a more volatile experience of 'reading', predicated on one of the Sl's most generative tactics of spatial disruption: the practice of dérive or drift.

38 Jorn and Debord, 2004, title page.

39 Idem. 
to create new constellations and to signify differently, in the same way that a specific mise-en-scene always transforms the so-called original meaning of any dramatic text. Debord's theatricalized sense of self shows that subjectivity is always in a state of constant re-arrangement, something environmental and transversal, in other words - a matter of being moved by those forces of the outside that so affected Chen and the Boatman in Weber's experience of Peking Opera.

14. Corresponding to Weber's corporeal and plastic notion of theatricality, Mémoires does not purport to tell a story. Instead, it communicates by transforming itself into a series of quasi-physical gestures or acts that spill over the page and remain alive in the very act of being looked at, taking on the weight and density of bodies. There is no transparency in Mémoires, no direct route into the soul of the characters or narrator. We simply flick through a chaotic series of individual pages, each of which insists on its own partiality and singularity, refusing to be consumed semantically into some totalising or unified historical narrative. The effect of these radical cuts and ellipses in the narration is to introduce a sense of flux and flow to the reading experience, which, in turn, creates movement and duration. In an insightful but short essay, Greil Marcus, without ever explicitly using the word, discloses the theatrical aspect of the work by insisting on its obsession with staging and erasing meaning. For Marcus, this continual calling into question of the act of communication endows Mémoires with a sense of impermanence and transience: "[T]he discovery of a true communication is also what the book is about - or at any rate it is the quest for such a communication, the adventure of finding it and losing it, that the book describes. Read in this way, the rhythm of Mémoires becomes one of isolation to contact, contact to community, community to broken contacts, broken contacts to isolation. In the course of that rhythm, subjects - individuals - become poeticized; so do objects - streets and buildings - and if the story itself does not leave a trace, the world will never quite look the same again." 40

Marcus's comments are attuned to the dramaturgical structure of Mémoires, the sense in which its collage of fragmented texts and chromatic anarchy collide into and with each other, producing, in the process, a discordant, syncopated rhythm. Perversely, this book is not something to be read but something to enter into and to be affected by, a 'scenography' or lively environment of sorts. ${ }^{41}$

15. In the early 2000s, a group of scholars, most notably Una Chaudhuri, Elinor Fuchs, and Hans Thies-Lehmann looked to make sense of the burgeoning number of theatre makers who drew, sometimes consciously and sometimes not, on the writings of Gertrude Stein to create new forms of non-narrative or post-dramatic performance. ${ }^{42}$ They did so by using the concept of landscape as

40 Marcus, 1989, 131.

41 For more contemporary attempts to theatricalize the page, see Inci Evener's extraordinary piece, Beuys Underground (2017) in which a flat LCD screen is transformed into a seething mass of digital bodies and objects in perpetual motion in a dystopian underground world.

42 Chaudhuri and Fuchs, 2002, 1-10; and Lehmann, 1997, 55-60. 
a device for describing the simultaneity of spaces and times that characterized the work of directors and companies such as Robert Wilson, Heiner Müller, the Wooster Group, and Jan Fabre. Chaudhuri, Fuchs, and Lehmann are useful thinkers to draw on, in this context. Mémoires not only transforms the page into a stage, as I suggested. More accurately, it figures that stage as a landscape. As in many examples of postdramatic performance, the eye is being constantly mobilized by the images and colours it gazes at, made rhythmic, forced to err and slide over the surface of things. In the process, the focus of attention moves from identifying with characters towards the development of a more expanded, ecology of perception in which experience is more in tune with natural processes and ecosystems. However, there is a key difference. In Mémoires, the territory that is established is provisional, always on the verge of giving way, collapsing in on itself. Such volatile deterritorializations, this uprooting of the eye, necessitate new ways of thinking through the theatricality of landscape as well as, perhaps, the very concept of landscape theatre itself. Henceforth, the onus is not so much on geography - moving from point to point, scanning through and across a relatively fixed landscape in largely visual terms - but on geology, learning how to inhabit a volatile planet of fault lines, eruptions and plate movements. For all its references to the natural world, landscape theatre, ultimately, leaves the spectator in the centre of things, the purveyor of all s/he sees. Geological theatre, by contrast, offers a more violent experience. In it, the world is fissured, and perception becomes vertiginous, lost in a whorl of movement.

\section{Isomorphism}

16. Consider an image - an image of a page. The page is assembled of a mass - a substance - of black marks that are piled on top of and alongside each other and assembled vertically and horizontally. This 'sedimented' matter is superimposed on a white surface and held together by two white or blank strata above and below it. As Deleuze and Guattari propose in their expanded notion of "stratigraphy" in Plateau 3 of A Thousand Plateaus (1981 [1987), there is something geological in any operation of ordering and extracting information. ${ }^{43}$ In the same way that a geologist conventionally 'reads' the earth by dividing strata into discrete periods of inhuman time, so readers engage in a similar operation of making sense of the words from the mass that confronts them. Matter is scanned, and data gleaned.

17. A conventional approach to the analogy that I am developing between earth and page above would be to see it as a metaphorical operation. Put simply, this is a linguistic process in which one object is compared to another and a relationship of similitude drawn - in this instance, the link between page and earth. The problem with metaphor, as many critics have pointed out, is that the drive to establish sameness results in an eradication of difference, and a largely artificial or conventional rapport is established between what are, in reality, two radically distinct substances. However, an alternative understanding of similitude

43 Deleuze and Guattari, 1987, 39-74. 
emerges if we shift the focus from metaphor to isomorph - a geometrical term that maps relations of equality - not identity - between apparently disparate sets and shapes. As opposed to the anthropocentric violence of metaphor, isomorphism does not simply posit resemblances at the level of objects and things, but, on the contrary, discloses equal patterns of formation at the level of process. Deleuze and Guattari term this operation an abstract or "machinic mode of composition" in which everything participates on an unrepresentable energetic plane, the "plane of consistency". ${ }^{44}$ In his appositely named text, $A$ Thousand Years of Nonlinear History (1997), the Deleuzian scholar Manuel DeLanda provides an accessible account of how isomorphism functions: "When we say (as Marxists used to say) that "class struggle is the motor of history", we are using the word "motor" in a purely metaphorical sense. However, when we say that a "hurricane is a steam motor" we are not simply making a linguistic analogy: rather we are saying that hurricanes embody the same diagram used by engineers to build steam motors - that is, we are saying that a hurricane, like a steam engine, contains a reservoir of heat, operates via thermal differences, and circulates energy and materials through a (so-called) Carnot cycle." 45

18. DeLanda's take on isomorphism, his diagrammatic account of the abstract motor, establishes common physical properties in such a way that distinctions between human and non-human nature are muddied, made fuzzy. For him, "reality is a single matter-energy undergoing phase transitions", and the "engine"" that drives and sorts the fluxes and flows of matter-energy, creates both similarities and differences. ${ }^{46}$ What we are left with, then, is a process of what Deleuze and Guattari in Anti-Oedipus: Capitalism and Schizophrenia (1972 [2004]) call "disjunctive synthesis", a oneness that eludes all totality, and is constantly splitting. ${ }^{47}$ Although it has nothing to do with rocks per se, the page, at an abstract level - the level of isomorphism - partakes in a similar geological operation of folding and sedimenting, an ordering of matter that is composed of strata and stratigraphy, forms and substances, structures and signs. It is also, as Deleuze and Guattari argue in their apt notion of "a geology of morals", something expressive: the strata of the page produce concepts, feelings, and affects - that is to say, ways of being on the earth. ${ }^{48}$

19. According to Deleuze and Guattari, stratification is a necessary process. It holds matter in place and creates territories. Without strata, the 'earth' for humans and animals would not exist. It would merely float free, a storm of atoms. However, if there is a danger in wild destratification, there is an equal danger in being too rigidly stratified, in overcoding matter, attempting to fix its expressive potential, to master it. In normative acts of western reading, little attention is given to the materiality of the page itself, the fact that it is made of

44 Ibid., 506-14.

45 DeLanda, 1997, 58; original italics.

46 Ibid., 58.

47 Deleuze and Guattari, 2004, 17-23.

48 Deleuze and Guattari, 1987, 40. 
elemental matter (crushed trees, plants, minerals, and bones), and neither is there much concern with the shape, texture or affective power of how the page is laid out. Nothing, in other words, is allowed to get in the way of transparent communication. Reading is an affair of the 'spirit', an intellectual exchange, a purely human phenomenon. This daily occlusion of the energy matter that drives all mediation is typical of the dangerous Prometheanism that has resulted in the Anthropocene. ${ }^{49}$ For what we are confronted with, the very thing that normative reading performs, is a forgetting of the fact that the earth is dynamic, volatile, and erratic - the type of earth that was initially theorized by Alfred Wegener in 1912 in his theory of 'continental drift' and finally accepted in the 1950s by the geological community. ${ }^{50}$ Instead of a planet that is subjected to internal and external drifting - the collision of continental plates, the gravitational pull of the moon, heat from the sun, etc. - the strata of the page suggest that the layers of the earth are stable, solid, inert matter there for us to use, to exploit as we will. This apparent passivity is something, of course, that the petroleum industry, in particular, has invested in and practised to the detriment of the planet, in general. For what the Anthropocene, with its warming climate and species extinctions shows, is that vertical reading has been superseded by horizontal reading. Everything is at play at the same time. The past has returned in the present and points to the future: climate change as 'temporal weirding'.

\section{Destratification}

20. Roughly contemporaneous with the acceptance of Wegener's theory of continental drift in the late 1950s, Mémoires explodes the stratigraphy the normative geology - of the western page by taking every opportunity to destratify the rigid geometries that keep the matter of language in place and the image of the earth so stable. It does so by allowing the text to drift, to become theatrical, transforming reading into an affair of earthly bodies - materialized signs - interacting and colliding. In Mémoires, this 'earthing' of the eye is seen in numerous ways that vary from page to page. On page 13, for instance, an amorphous splash of purple ink dominates the surface area of the page, moving outwards from the centre, where it is at its thickest and most opaque, to the margins where it peters out in thin spots, scrawls, and splatters. ${ }^{51}$ In the lower middle section of the page, a piece of found text - an extract from a newspaper - has been violently arranged in such a way that it is impossible to make out, fully, what the writing refers to or indeed where it has come from. By cutting up the original text and arranging the sentences so that some of the lines and words are superimposed on top of each other asymmetrically, the eye is constantly frustrated in its attempt to decipher what has been laid down as

49 Prometheanism refers to an unbridled sense of optimism in humanity's ability to 'tame' the earth, technologically.

50 Against the idea of geological fixity, Wegener argued that the continental plates of the earth moved and drifted across the sea bed, and thus changed place and shape over vast aeons of time. 51 There are no listed page numbers in Mémoires, I have simply counted the pages as they unfold in series. To access an on-line copy of the facsimile, including the pages described above, see https://www.academia.edu/11522988/Memoires_-_Guy_Debord_and_Asger_Jorn_English_ Facsimile_. Date of access (15 October, 2019). 
sediment. Rather, it finds itself confronted with a fissured stratigraphy, one in which individual words fragment and no longer conjugate to make up a sentence. Visually, the text resembles a fault-line, a sudden surge and accumulation of matter that appears to have been caught in a pincer movement of plates from below and pushed up in such a way that the strata of the page has been contorted and dislocated. In this collision, semantics gives way to theatricality, and the reader staggers through a splintering mass of colour, texture, and shape. In this geomorphology, this landscape that trembles and shakes, the page is not something we inhabit or own, as the etymology of the Latin word pagus may suggest (in Latin, pagus signifies a clearly demarcated administrative territory such as a region). On the contrary, it is an energetic environment, a milieu that implicates us in what Weber refers to as theatricality's "sway of being".

21. A varied but nevertheless similar experience is constructed for the reader on page 24. Whereas page 13 was dominated by an explosion of purple with an asymmetrically designed piece of cut-up text below it, page 24 is splattered, violently, with an excess of visual and textual shards of different fonts, shapes, textures, and provenances that are stained by irregular blotches - drippings of vibrant orange ink. On the four corners of the page, framing the texts, there are four photographs of anonymous protagonists: two thumbnails of two men at the top and bottom of the page; a larger profile shot of a young woman on the left-hand side; and, on the right, an image of young people drinking in a café and gazing into the aperture of the camera. Breaking, as every page of Mémoires does, with the domesticating strata of the conventional page, the diverse fragments do not follow one another in linear or horizontal fashion. Rather, they have been emancipated from all stratified order. The geometry and geology of meaning has broken apart, and been permitted to float free, to fluctuate, to become topological. On the top half of the page, lines from the pirate song in Robert Louis Stevenson's Treasure Island sit above a cut-up newspaper article about 1920s' Paris. This assemblage, in turn, collides with an arbitrary quotation stating that "on a du génie à vingt ans", which, itself, is positioned beneath a larger, more legible fragment contesting statistics of adolescent girls who have run away from home and become sex workers. ${ }^{52}$ The lower part of the page depicts a similar scene with a lengthy cut-up text from a newspaper, constellated with a series of short, nugatory citations from poems and novels and a list of questions from a careers service questionnaire for future adolescent employees, written in italics. On the extreme right-hand side of the page, there is a reproduction of a drawing of a volcano taken from a high-school primer in which we see a graphic illustration of tectonic plates colliding and slipping over each other to form a crater, and presumably a flow of magma. The choice of image is telling. Not only does it encapsulate, in graphic form, a semantic line - a geologic trope, we could say - that runs throughout Mémoires and infuses the entire text with an overarching sense of violent earth movements ("agitations", "tremblings", "crashings", "shakings", "collisions", etc.). It also exists as a metatheatrical figure that comments on how the book

52 Jorn and Debord, 2004, 13. 
operates. In both instances, the image acts as a connector, a device or plane that brings together the human and non-human, underlining the notion that to exist today is to inhabit a drifting, agentic earth.

\section{Drifting}

22. This geological reading of Mémoires as an earth book in movement, an exercise in Wegener's plate tectonics, transforms radically our understanding of what drifting or the dérive means in the Anthropocene. In Situationist parlance, the drift was proposed as a walking practice that sought to perform the city differently. ${ }^{53}$ At a time when the urban landscapes of Europe were being rebuilt and depopulated in order to allow for the smooth circulation of cars and capital, the drift was originally intended to place the body at the heart of the city. The aim behind this re-corporealisation of everyday experience was to posit physical sensation in the city as something collective, pleasurable, and political. In Guy Debord's 1958 text 'Theory of Dérive' the drift is defined as: "[A] technique of rapid passage through varied ambiences. Dérives involve playful constructive behaviour and awareness of psychogeographical effects, and thus are quite different from the classic notions of journey or stroll. In a dérive one or more persons during a certain period drop their relations, their work and leisure activities, and all their other usual motives for movement and action, and let themselves be drawn by the attractions of the terrain and the encounters they find there." 54

And for Ivan Chtcheglov, the first theorist of the dérive, the drift was imagined as a type of sacred ecstasy, an end in itself. "A mental disease has swept the planet: banalization. Everyone is hypnotized by production and conveniences - sewage systems, elevators, bathrooms, washing machines [....]. It has become essential to provoke a complete spiritual transformation by bringing to light forgotten desires and by creating entirely new ones. And by carrying out an intensive propaganda in favor of these desires." 55

Understandably, perhaps, and given its political aspirations, the majority of writing on the SI has approached the drift as a humanist, predominantly Hegelian-inspired practice, in which individual agents - or drifters - are able to re-appropriate an alienated reality. ${ }^{56}$ However, in the Anthropocene, the drift, as I have intimated, takes on a different, more expanded significance. No longer confined to the socio-political domain, the dérive is now figured as something that impacts on human subjects, threatening to sweep them away. As Bronislaw Szerszynski explains, the drift is important in the Anthropocene to the extent that it points to "the primordial power of the Earth, full of both manifest and latent powers". ${ }^{57}$

53 I am also aware that the term 'drift' in post-gradualist geology refers to "the surfical detritus of unconsolidated layers of unconsolidated sediments, such as boulders, gravel, sand, silt and clay, that lie atop and obscure the consolidated layers of rock we refer to as strata". Dixon, 2018,13.

54 Debord, in Knabb, 2006, 62.

55 Chtcheglov, in Knabb, 2006, 4.

56 Sadler, 1998, and McDonough, 2010, provide the most detailed readings of the humanism inherent to the SI projects of urban re-appropriation.

57 Szerszynski, 2018, 143. 
23. The new idea of drift that Szerszynski articulates transforms, necessarily, our approach to Mémoires. In the Anthropocene, it is not enough to consider how Jorn and Debord represent drift in terms of a politics of text and image, as all critics have done to date.$^{58}$ Rather, the contemporary onus is on 'reading' Mémoires geolithically, in a way that expresses what it means to live on a planet in constant movement, an earth whose indiscernible but intensive pressure is foregrounded in its organisation of the surface of the page, in what I have called its theatricality. By folding us into the book and subjecting us to its staggered, arhythmic motion, Jorn and Debord allow for a different memory to emerge. Ultimately, this is not human memory, memory that centres on and emanates from the interiority of the subject or even from a cultural collective; rather, it is Anthropocene memory, recall that comes from the outside, and which emerges from the return of some repressed geological unconscious. This return equates with an awareness that the earth is neither ours to master nor to survey.

24. In Mémoires, the earth is effectively groundless, a churning mass of magma and rock that undoes the strata that would hold it together and give it a sense of solidity and structure. This groundlessness, which Jorn and Debord can rightly only express rather than represent, reconfigures, by necessity, what we may call our 'ecological habitus' in the Anthropocene by endowing the earth with an agency that is dangerous to dismiss and impossible to sentimentalize. Equally, it asks us to rethink what we mean by reading in the Anthropocene. Instead of seeing reading as a transparent exercise in communication, it is incumbent upon us to approach it as an exercise in plate tectonics, something that moves us. In this way, reading is no longer simply confined to hermeneutics, it is now opened up to theatricality, a suspensive disclosure that allows it to be haunted by the elemental energies of the earth itself. And it is exactly here, I wager, in this awareness of the earth as a creative but anarchic force, as a drifting work, in other words, that theatricality can make its own singular contribution to how we may learn to live better in the Anthropocene.

58 Mémoires has generally been read in two ways. Either critics pay attention to the politics of the text (see Donné, 2004 and Mudie, 2016); or to the image (see Gilman, 2002 and Kurczynski, 2012). No one has yet thought to read it as an earth book, an exercise in what we could now term 'psychogeology'. 


\section{AUTHOR}

Carl Lavery is Professor of Theatre and Performance at the University of Glasgow. $\mathrm{He}$ has written extensively on theatre and performance, and his most recent work has been on 'drifting' and the 'new animism' for the journal Performance Research, of which he is an associate editor. This research was funded by an AHRC/LABEX grant. Reviewing Spectacle: The Pasts, Presents and Futures of the Situationist International in Contemporary Performance (AH/N504592/1).

\section{REFERENCES}

Arons, Wendy and Theresa J. May (eds). 2012. Readings in Performance and Ecology. Basingstoke: Palgrave Macmillan.

Bellamy Foster, John. 1999. "Marx's Theory of Metabolic Thrift: Classical Foundations for Environmental Sociology". American Journal of Sociology 105: 2, 366-404.

Bonneuil, Christophe and Jean-Baptiste Fressoz. 2016. The Shock of the Anthropocene: The Earth, History and Us. Translated by David Fernbach. London: Verso.

Bottoms, Stephen and Matthew Goulish (eds). 2007. Small Acts of Repair: Performance, Ecology and Goat Island. London and New York: Routledge.

Braddock, Christopher (ed). 2017. Animism in Art and Performance. Basingstoke: Palgrave Macmillam.

Burns Elizabeth. 1972. Theatricality: A Study of Convention in the Theatre. London: Longman.

Chaudhuri, Una. 1995. Staging Place: The Geography of Modern Drama. Ann Arbor: University of Michigan Press.

Chaudhuri, Una. 2016. The Stage Lives of Animals: Zooesis and Performance. London and New York: Routledge.

Chaudhuri, Una and Elinor Fuchs (eds). 2002. Land/Scape/Theater. Ann Arbor: University of Michigan Press.

Chtcheglov, Ivan. 2006 [1953]. “Formulary for a New Urbanism'. Translated by Ken Knabb. In Ken Knabb (ed.). Situationist International Anthology. Berkeley, CA: Bureau of Public Secrets, $1-4$.

Clark, Nigel. 2011. Inhuman Nature: Sociable Life on a Dynamic Planet. London: Sage.

Clark, Nigel and Kathryn Yusoff (eds). 2017. "Introduction: Geosocial Formations and the 
Anthropocene". Theory, Culture \& Society 34:2-3, 3-23.

Clark, Timothy. 2015. Ecocriticism on the Edge: The Anthropocene as a Threshold Concept. London: Bloomsbury.

Cohen, Tom. 2012. "Polemos 'I Am at War with Myself' or 'Deconstruction in the Anthropocene?". Oxford Literary Review 34:2, 239-57.

Crist, Eileen. 2016. "On the Poverty of Our Nomenclature". In Jason W. Moore (ed.). Anthropocene or Capitolocene? Nature, History and the Crisis of Capitalism. Oakland: Kairos, PM, 14-33.

Crutzen, Paul, J. 2002. "Geology of Mankind". Nature 415 (January), 23.

Davis, Tracy, C. and Thomas Postlewait (eds). 2003. Theatricality. Cambridge: Cambridge University Press.

DeLanda, Manuel. 1997. A Thousand Years of Nonlinear History. New York: Zone Books.

Debord, Guy. 2006 [1958]. "Theory of the Dérive". Translated by Ken Knabb. In Ken Knabb (ed.). Situationist International Anthology. Berkeley, CA: Bureau of Public Secrets, 50-4.

Deleuze, Gilles. 1998 [1993]. Essays Critical and Clinical. Translated by Daniel W. Smith and Michael A. Greco. Minneapolis: University of Minnesota Press.

Deleuze. Gilles and Félix Guattari. 1987 [1981]. A Thousand Plateaus. Capitalism and Schizophrenia 2. Translated by Brian Massumi. Minneapolis: University of Minnesota Press.

Deleuze, Gilles and Félix Guattari. 2004 [1972). Anti-Oedipus: Capitalism and Schizophrenia 1. Translated by Robert Hurley et al. London: Continuum.

Dixon, Deborah. 2018. "The Perturbations of Drift in a Stratified World". Performance Research $23: 7,130-5$.

Donné, Boris. 2004. Pour Mémoires. Paris: Allia.

Evener, Inci, 2017. Beuys Underground.

Féral, Josette. 2002. "The Specificity of Theatrical Language". Substance $31: 2$. 94-108.

Fischer-Lichte, Erika. 1995. "Theatricality : A Key Concept in Theatre and Cultural Studies". Theatre Research International". $20: 2,85-9$.

Gilman, Clare. 2002. "Asger Jorn's Avant-Garde Archives». In Tom McDonough (ed.). Guy Debord and the Situationist International: Texts and Documents. Cambridge, MA: MIT Press, 189-212.

Goffman, Erving. 1990 [1957] The Presentation of Self in Everyday Life. London: Penguin. 
Guattari, Félix. 2008 [1989]. The Three Ecologies. Translated by lan Pindar and Paul Sutton. London: Continuum.

Haraway, Donna. 2016. Staying with the Trouble: Making Kin in the Chthulucene. Durham, NC: Duke University Press.

Hornborg, Alf. 2015. "The Political Ecology of the Technocene: Uncovering Ecologically Unequal Exchange in the World System". In Clive Hamilton et al (eds). The Anthropocene and the Global Environmental Crisis: Rethinking Modernity in a New Epoch. London: Routledge, 57-69.

Jorn, Asger and Guy Debord. 1957. Fin de Copenhague. Copenhagen: Permild \& Rosengreen. Jorn, Asger and Guy Debord. 2004 [1958]. Mémoires. Paris: Allia.

Kershaw, Baz. 2007.Theatre Ecology: Environments and Performance Events. Cambridge: Cambridge University Press.

Knabb, Ken. 2006. Situationist International Anthologogy, Revised and Expanded Edition. Berkeley, CA: Bureau of Public Secrets.

Kurczynski, Karen. 2012. "No Man's Land". October 141, 22-52.

Lehmann, Hans-Thies. 1997. "From Logos to Landscape: Text in Contemporary Dramaturgy". Performance Research 2:1, 55-60.

Madie, Ella. 2016. "An Atlas of Illusions: The Perverse Methods of Guy Debord's Mémoires". Criticism 58: 4, 535-63.

Marcus, Griel. 1989. "Guy Debord's Mémoires: A Situationist Primer". In Elizabeth Sussman (ed.). On the Passage of a Few People Through a Rather Brief Moment of Time: The Situationist International 1957-1972. Cambridge, MA: 1989, 125-31.

Marranca, Bonnie. 1996. Ecologies of Theater. Baltimore: John Hopkins Press.

McDonough, Tom (ed.). 2010. The Situationists and the City. London: Verso.

Moore, Jason W. (ed.). [2016] Anthropocene or Capitolocene? Nature, History and the Crisis of Capitalism. Oakland: Kairos, PM.

Orozco, Lourdes. 2013. Theatre \& Animals. Basingstoke: Palgrave Macmillan.

Read, Alan. 2009. Theatre, Intimacy \& Engagement: The Last Human Venue. Palgrave Macmillan.

Sadler, Simon. 1998. The Situationist City. Cambridge, MA: MIT Press.

Salazar Sutil, Nicolás. 2018. Matter Transmission: Mediation in a Paleocyber Age. London: Bloomsbury. 
Schweitzer, Marlis and Joanne Zerdy (eds). 2014. Performing Objects and Theatrical Things. Basingstoke: Palgrave Macmillan.

Stiegler, Bernard. 2018. The Neganthropocene. Translated and foreword by Daniel Ross. London: Open Humanities Press.

Szerszynski, Bronislaw. 2018. "Drift as Planetary Phenomenon". Performance Research 23:7, 136-44.

Weber, Samuel. 2004. Theatricality as Medium. New York: Fordham. 